\title{
Antibiotic-resistant Salmonella species and Escherichia coli in broiler chickens from farms, abattoirs, and open markets in selected districts of Zambia
}

\author{
Nelson Phiri*1,2, Geoffrey Mainda ${ }^{3}$, Mercy Mukuma ${ }^{4}$, Ntazana N. Sinyangwe ${ }^{2}$, Luke J. Banda ${ }^{2}$, Geoffrey Kwenda ${ }^{5}$, \\ Elizabeth M. Muonga ${ }^{1,6}$, Bumbangi N. Flavien ${ }^{7}$, Mwaba Mwansa $^{5}$, Kaunda Yamba ${ }^{8}$, Musso Munyeme ${ }^{6}$, John B. \\ Muma 6 \\ ${ }^{1}$ Department of Environmental Health, School of Medicine and Health Sciences, Eden University, Lusaka, Zambia \\ ${ }^{2}$ Department of Environmental Health, School of Public Health, University of Zambia, Lusaka, Zambia \\ ${ }^{3}$ Department of Veterinary Services, Public Health Unit, Ministry of Fisheries and Livestock, Lusaka, Zambia \\ ${ }^{4}$ Department of Food Science and Nutrition, School of Agricultural Sciences, University of Zambia, Lusaka, Zambia \\ ${ }^{5}$ Department of Biomedical Sciences, School of Health Sciences, University of Zambia, Lusaka, Zambia \\ ${ }^{6}$ Department of Disease Control, School of Veterinary Medicine, University of Zambia, Lusaka, Zambia \\ ${ }^{7}$ Department of Disease Control and Prevention, School of Medicine and Health Sciences, Eden University, Lusaka, Zambia \\ ${ }^{8}$ Department of Pathology and Microbiology, Bacteriology Unit, University Teaching Hospitals, Ministry of Health, Zambia
}

Received: August 11, 2020

DOI: $10.5430 /$ jer.v6n1p13
Accepted: September 14, 2020 Online Published: September 25, 2020

URL: https://doi.org/10.5430/jer.v6n1p13

\begin{abstract}
Objective: Salmonella species and Escherichia coli are major bacterial enteropathogens of worldwide public health importance that cause devastating foodborne diseases, thereby contributing to increased human morbidity and mortality. Both pathogens have also been found to contribute towards the spread of antimicrobial resistance through the food chain, especially in poultry. This study aimed to determine the occurrence of antibiotic-resistant Salmonella spp. and E. coli in broiler chickens at farm level, abattoirs, and open markets in selected districts of Zambia.

Methods: A cross-sectional study was undertaken in seven districts of Zambia to determine the resistance profiles of Salmonella spp. and E. coli obtained from broiler chickens at farms, abattoirs, and open markets. A total of 470 samples were collected which include; litter, cloacal swabs, and carcass swabs. Samples were inoculated into buffered peptone water and incubated for 24 hours then sub-cultured onto MacConkey and Xylose Lysine Deoxycholate agar plates. Identification of Salmonella spp. and $E$. coli was done using the API-20E kit and confirmation by $16 \mathrm{~S}$ rDNA sequencing. Confirmed isolates were tested against a panel of 09 antibiotics using the Kirby-Bauer disc diffusion method and interpreted according to the Clinical Laboratory Standards Institute guidelines. Data analysis of the antibiotic sensitivity test results was done using WHONET 2018 software.

Results: Overall, 4 Salmonella spp. and 280 E. coli were isolated. One of the Salmonella spp. was resistant to ampicillin (25\%), amoxicillin/clavulanic acid (25\%), and cefotaxime (25\%). E. coli antibiotic resistance was highest to tetracycline (81.4\%) and $100 \%$ susceptibility to imipenem. The antibiotic susceptibility profile revealed 75.7\% (237/280) multidrug-resistant (MDR). The highest MDR profile was observed in 8.2\% (23/280) isolates in which 6 out of the 9 classes of antibiotics tested were resistant. Out of the 280 isolates, $11.4 \%$ (32/280) exhibited Extensive Drug resistance (XDR).

Conclusion: The study found antimicrobial resistance to E. coli and Salmonella spp. in market-ready broiler chickens which were resistant to important antibiotics and is of public health concern.
\end{abstract}

Key Words: Escherichia coli, Salmonella spp., Antibiotic-resistant, Broiler chickens

*Correspondence: Nelson Phiri; Email: nphiri39@yahoo.com; Address: Eden University Zambia, P.O Box 37727, Barlastone Park, Lusaka, Zambia. 


\section{INTRODUCTION}

Poultry production is one of the most important activities in the livestock sector in many countries, including Zambia. Production of chicken meat requires great care to assure food safety. Disease burden has, however, remained a great challenge in poultry production. ${ }^{[1]}$ Some of the common microbial pathogens that have been isolated from fresh poultry meat include Salmonella spp., Campylobacter spp. and Escherichia coli. ${ }^{[2]}$ Failure to manage these pathogens in poultry has led to various food-borne disease outbreaks in countries such as South Africa and Botswana, ${ }^{[3,4]}$ as well as in the United States. ${ }^{[5]}$

Even though progress is being made in the control of these pathogens, they tend to evolve and generate new challenges such as antibiotic resistance. ${ }^{[6]}$ Further, the use of antibiotics has been reported by scholars to be an important factor in the emergence, selection and spread of antibiotic-resistant pathogens in human and veterinary medicine. ${ }^{[7]}$ Antibiotic usage selects for resistance in pathogenic bacteria and the endogenous bacterial flora of exposed animals and humans. ${ }^{[8]}$ Resource-constrained countries face challenges that co-exist and facilitate the spread of bacteria during livestock production, transportation, and processing. These challenges include high bird population density in poultry houses and/or poor infection control measures such as lack of vaccinations and poor biosecurity. ${ }^{[9]}$

In Zambia, poultry is currently the main meat consumed by the population, totalling an estimated 50 percent of the total meat consumption in the country. For this reason, the poultry industry is one of the most important sectors in the growth of the country's economy contrary to the common perception that most people have about it. The Zambian poultry industry has been one of the fastest-growing subsectors of the livestock sector, it produces a variety of protein-containing foods such as chickens, eggs, and many others. ${ }^{[10]}$ According to the Poultry Association of Zambia (PAZ), the Zambian poultry industry has grown to move the country from importation of poultry products to a state of self-sufficiency. The industry generates 5 percent of the national Gross Domestic Product (GDP) and an estimated 47 percent of the livestock GDP. ${ }^{[10]}$

Processing plants such as abattoirs are still facing challenges in producing wholesome and safe food of animal origin for human consumption due to contaminations by antibioticresistant bacteria. ${ }^{[11]}$ This is partly because some poultry farmers are using antibiotics as growth promoters, which are perceived as an inexpensive management practice, ${ }^{[12]}$ while other farmers use antibiotics in disease prevention as a mitigation measure against the highly prevalent unhygienic conditions and absence of biosecurity ${ }^{[13]}$ Consequently, an14 tibiotics are found in meat as residues and bacteria are continuously being exposed to them with a risk of developing resistance. ${ }^{[14]}$ This study was, therefore, carried out to determine the occurrence of antibiotic-resistant Salmonella spp. and $E$. coli isolated from broiler chickens that are intended for human consumption at farm level, abattoirs, and open markets in selected districts of Zambia.

\section{MATERIALS AND METHODS}

\subsection{Study design, site, and population}

A cross-sectional study was conducted from December 2017 to June 2018 to investigate the occurrence of antibioticresistant Salmonella spp. and E. coli in broiler chickens from poultry farms, commercial abattoirs, and open markets. Litter and cloacal swab samples were collected from 7 districts: Chilanga, Chongwe, Kafue, Lusaka (Lusaka Province), Choma (Southern Province), Kabwe (Central Province), and Kitwe (Copperbelt Province). In Lusaka Province, only two commercial poultry abattoirs gave consent to the study. In Choma, Kitwe, and Kabwe, were no poultry abattoirs were available, freshly voided fecal droppings from market-ready broiler chickens and cloacal swab samples were collected from farms and open markets. Chickens that were condemned at slaughter or point of sale were excluded from the study.

\subsection{Sample size and sampling technique 2.2.1 Poultry houses}

In all the districts included in the study, there was no information on the number of farmers who reared broiler chickens as most of whom were seasonal farmers. A seasonal farmer was defined as the farmer who keeps broiler chicken when the production parameters including the cost of feed, cost of medicines are favourable and stops when they are not. Therefore, a convenience snowball sampling method was used, and farmers in production were initially identified with the help of a local veterinary assistant or livestock officer. Such farmers would then lead to other farmers in the season of production. At each farm, several poultry litter portions (one sample per $25 \mathrm{~m}^{2}$ ) were collected from each poultry house and pooled for laboratory analysis. Using this technique, a total of 212 pooled litter samples were collected from the following districts: Chilanga $(n=31)$, Chongwe $(n=23)$, Kafue ( $n=33)$, Lusaka $(n=24)$, Choma $(n=17)$, Kabwe ( $=39)$ and Kitwe $(n=45)$.

\subsubsection{Abattoirs}

A total of two abattoirs were included in this study. Three cloacal and three carcass swabs were collected from each batch of chickens supplied to each of the abattoirs. Only 25 farmers supplied chickens during the period of study. Ten 
(10) and fifteen (15) farmers were sampled from abattoir A and $\mathrm{B}$, respectively. The two (2) were the main abattoirs in the study area and supplied poultry meat to supermarkets and open markets throughout the country. A random "blind" sampling method was used to select the 3 chickens and cloacal swabs. This method was used as it yields information about the average composition of the lot. It is employed when there is no information or method for determining which units (bacterial pathogens) are violated. ${ }^{[15]}$ A total number of 150 samples were collected from the two abattoirs, comprising 75 cloacal swabs collected in the receiving bay before hosting the birds on the hackles (targeting bacteria originating from farms) and 75 carcass swabs collected during the packaging process before the carcasses were chilled (to ascertain the efficiency of processing and cross-contamination). Carcass swabs were collected from under the wings of the chicken where the bacterial population is thought to concentrate during processing. ${ }^{[16]}$

\subsubsection{Open Markets}

Choma, Kabwe, and Kitwe districts did not have any abattoir at the time of sampling. Therefore, only broiler chickens sold on open markets were available for cloacal swab collection. Samples were collected from chickens of all vendors available on the day of the visit. The random "blind" sampling method was equally used at these sites. A total of 108 cloacal swabs were collected with the following distribution: Choma 35 samples, Kabwe 40 samples, and Kitwe 33 samples. All samples were immediately transferred into Amie's transport media (Oxoid, Basingstoke, UK) in a cool box with ice packs and transported to the Public Health Laboratory at the University of Zambia, School of Veterinary Medicine for analysis. Samples were processed and analyzed within 24 hours of collection.

\subsubsection{Laboratory analysis}

Laboratory analysis included isolation of Salmonella spp. and $E$. coli, identification, confirmation of the isolates, and antibiotic susceptibility testing (AST). Laboratory protocols for bacterial isolation recommended by the Food and Drug Administration's Bacteriological Analytical Manual were used with few modifications. ${ }^{[15,17]}$ All media used were prepared according to the manufacturer's instructions. The media were quality controlled using control strains $E$. coli ATCC 25922 and Salmonella typhimurium ATCC 14028.

\subsubsection{Isolation and identification of Salmonella species}

Litter and swabs samples were pre-enriched in $10 \mathrm{ml}$ buffered peptone water (Oxoid, Basingstoke, UK) and incubated at $37^{\circ} \mathrm{C}$ for 24 hours. Aliquots from the pre-enrichment broth were inoculated into the Rappaport Vassiliadis medium (Oxoid, Basingstoke, UK), a selective enrichment medium for
Salmonella spp., at a ratio of $1: 10$ and incubated at $37^{\circ} \mathrm{C}$ for 48 hours. A loop full of enriched broth was streaked on Xylose Lysine Deoxycholate (XLD) agar plates (Oxoid, Basingstoke, UK) and incubated aerobically at $37^{\circ} \mathrm{C}$ for 18 24 hours. The presumptive identification of Salmonella spp. was based on the morphological characteristics of colonies of non-lactose fermenters. Suspected colonies of Salmonella spp. from each plate were subjected to serological testing using polyvalent serum against $\mathrm{O}$ and $\mathrm{H}$ antigens. Presumptive Salmonella spp. colonies were then sub-cultured on nutrient agar plates (Oxoid, Basingstoke, UK), incubated at $37^{\circ} \mathrm{C}$ for 18 to 24 hours, and the resulting pure colonies subjected to biochemical identification using the API-20E test kit (bioMérieux, Marcy I'Etoile, France) according to the manufacturer's instructions. The identity of the isolates was confirmed by sequencing of the bacterial $16 \mathrm{~S}$ rDNA gene. ${ }^{[18]}$

\subsubsection{Isolation and identification of $E$. coli}

For the isolation of E. coli, litter and swabs samples were placed in $10 \mathrm{~mL}$ of buffered peptone water (Oxoid, Basingstoke, UK) as a pre-enrichment media and incubated at $37^{\circ} \mathrm{C}$ for 24 hours. Aliquots from the pre-enrichment broth were sub-cultured onto MacConkey agar plates (Oxoid, Basingstoke, UK) and incubated aerobically for an additional $18-24$ hours at $37^{\circ} \mathrm{C}$. Lactose fermenting colonies were then sub-cultured onto Eosin Methylene Blue (EMB) agar plates (Oxoid, Basingstoke, UK) and incubated aerobically at $37^{\circ} \mathrm{C}$ for $18-24$ hours. After incubation, presumptive $E$. coli colonies were observed to have a distinct green metallic sheen and confirmed by using the API-20E test kit and $16 \mathrm{~S}$ rDNA sequencing as described for Salmonella isolates. ${ }^{[19]}$ All isolates were placed in $10 \%$ glycerol and stored at $-20^{\circ} \mathrm{C}$ for a short period until AST was done.

\subsubsection{Antibiotic sensitivity testing}

The antibiotic susceptibility testing was done using the Kirby-Bauer disc diffusion method on Müeller-Hinton agar plates (Oxoid, Basingstoke, UK). ${ }^{[20]}$ Cell suspension densities equal to $0.5 \mathrm{McF}$ arland turbidity were prepared from fresh, pure cultures of either Salmonella spp. or E. coli isolates grown overnight using a Nephelometer. Using a sterile swab, the bacterial suspensions were then evenly inoculated on the surface of the Müller-Hinton agar plates (Oxoid, Basingstoke, UK). The following antibiotics, of both veterinary and human health importance, were used: amoxicillin-clavulanic acid (30 $\mu \mathrm{g})$, ampicillin $(10 \mu \mathrm{g})$, tetracycline $(30 \mu \mathrm{g})$, chloramphenicol $(30 \mu \mathrm{g})$, cefotaxime (30 $\mu \mathrm{g})$, ciprofloxacin $(5 \mu \mathrm{g})$, nalidixic acid $(30 \mu \mathrm{g})$, imipenem $(10 \mu \mathrm{g})$ and trimethoprim-sulphamethoxazole $(30 \mu \mathrm{g})$. The choice of these antibiotics was based on a list of essential drugs recommended and prioritized by WHO/OIE. ${ }^{[21]}$ The plates were incubated for $18-24$ hours at $37^{\circ} \mathrm{C}$. The zones 
of inhibition were read using a digital Vernier Calliper and interpreted as Susceptible (S), Intermediate (I), and Resistant $(\mathrm{R})$ based on the Clinical Laboratory Standards Institute recommendations. ${ }^{[22]}$ Multi-Drug Resistant (MDR) and Extensive Drug Resistant (XDR) isolates were identified in this study. In this study, MDR was defined as non-susceptibility to three or more antimicrobial classes of antibiotics tested ${ }^{[23]}$ while XDR was defined as non-susceptibility in all but 2 or fewer antibiotic categories in the antibiotic classes tested per international expert proposal for interim standard definitions for resistance. ${ }^{[23]}$

\subsubsection{Data processing and analysis}

The recorded zones of inhibition for AST were entered and analysed using WHONET software. Frequency distribution was reported for all categories as well as proportions and profiles of antibiotic resistance.

Table 1. Distribution of Salmonella spp. and E. coli isolates by location

\begin{tabular}{|c|c|c|c|c|c|c|c|c|}
\hline \multirow[b]{2}{*}{$\begin{array}{l}\text { Sampling } \\
\text { areas }\end{array}$} & \multicolumn{3}{|c|}{ Salmonella spp. } & & \multicolumn{3}{|c|}{ E. coli isolates } & \multirow[b]{2}{*}{$\begin{array}{l}\text { Total } \\
\%(n)\end{array}$} \\
\hline & $\begin{array}{l}\text { Litter } \\
\text { swabs } \\
\%(n)\end{array}$ & $\begin{array}{l}\text { Cloaca } \\
\text { swabs } \\
\%(n)\end{array}$ & $\begin{array}{l}\text { Carcass } \\
\text { swabs } \\
\%(n)\end{array}$ & $\begin{array}{l}\text { Total } \\
\%(n)\end{array}$ & $\begin{array}{l}\text { Litter } \\
\text { swabs } \\
\%(n)\end{array}$ & $\begin{array}{l}\text { Cloaca } \\
\text { swabs } \\
\%(n)\end{array}$ & $\begin{array}{l}\text { Carcass } \\
\text { swabs } \\
\%(n)\end{array}$ & \\
\hline $\begin{array}{l}\text { Abattoir } \\
\text { A }\end{array}$ & - & $0(0 / 30)$ & $0(0 / 30)$ & $0(0 / 60)$ & - & $\begin{array}{l}66.7 \\
(20 / 30)\end{array}$ & $\begin{array}{l}56.7 \\
(17 / 30)\end{array}$ & $\begin{array}{c}61.7 \\
(37 / 60)\end{array}$ \\
\hline $\begin{array}{l}\text { Abattoir } \\
\text { B }\end{array}$ & - & $4.4(2 / 45)$ & $4.4(2 / 45)$ & $4.4(4 / 90)$ & - & $\begin{array}{c}91.1 \\
(41 / 45)\end{array}$ & $\begin{array}{l}88.9 \\
(40 / 45)\end{array}$ & $\begin{array}{c}90.0 \\
(81 / 90)\end{array}$ \\
\hline Lusaka & $0(0 / 24)$ & - & - & $0(0 / 24)$ & $50.0(12 / 24)$ & - & - & $\begin{array}{c}50.0 \\
(12 / 24)\end{array}$ \\
\hline Choma & $0(0 / 17)$ & $0(0 / 35)$ & - & $0(0 / 52)$ & $76.4(13 / 17)$ & $\begin{array}{c}31.4 \\
(11 / 35)\end{array}$ & - & $\begin{array}{c}46.2 \\
(24 / 52)\end{array}$ \\
\hline Kabwe & $0(0 / 39)$ & $0(0 / 40)$ & - & $0.0(0 / 79)$ & $84.6(33 / 39)$ & $\begin{array}{c}35.0 \\
(14 / 40)\end{array}$ & - & $\begin{array}{c}59.5 \\
(47 / 79)\end{array}$ \\
\hline Kitwe & $0(0 / 45)$ & $0(0 / 33)$ & - & $0(0 / 78)$ & $53.3(24 / 45)$ & $\begin{array}{c}42.4 \\
(14 / 33)\end{array}$ & - & $\begin{array}{c}48.7 \\
(38 / 78)\end{array}$ \\
\hline Chilanga & $0(0 / 31)$ & - & - & $0.0(0 / 31)$ & $45.2(14 / 31)$ & - & - & $\begin{array}{c}45.2 \\
(14 / 31)\end{array}$ \\
\hline Kafue & $0(0 / 33)$ & - & - & $0.0(0 / 33)$ & $54.5(18 / 33)$ & - & - & $\begin{array}{c}54.5 \\
(18 / 33)\end{array}$ \\
\hline Chongwe & $0(0 / 23)$ & - & - & $0.0(0 / 23)$ & $39.1(9 / 23)$ & - & - & $\begin{array}{c}39.1 \\
(9 / 23)\end{array}$ \\
\hline Total & $\begin{array}{l}0.0 \\
(0 / 212)\end{array}$ & $\begin{array}{l}1.1 \\
(2 / 183)\end{array}$ & $2.7(2 / 75)$ & $\begin{array}{c}0.9 \\
(4 / 470)\end{array}$ & $\begin{array}{l}58.0 \\
(123 / 21)\end{array}$ & $\begin{array}{c}54.6 \\
(100 / 183)\end{array}$ & $\begin{array}{c}76 \\
(100 / 183)\end{array}$ & $\begin{array}{c}59.6 \\
(280 / 47)\end{array}$ \\
\hline
\end{tabular}

\section{Results}

\subsection{Isolation and identification of bacteria}

Salmonella spp. and E. coli were the bacteria of interest. Overall, out of the 470 samples collected, $59.6 \%$ (280/470) were E. coli and $0.9 \%$ (4/470) were Salmonella spp. The occurrence of the two pathogens per sample type and areas of sampling are shown in table 1 above. Out of the 212 litter samples collected from the poultry houses in the selected districts in this study, $58.0 \%$ (123/212) E. coli were isolated but no Salmonella spp. were isolated. E. coli was mostly isolated in Kabwe 84.6\% (33/39) and Choma 76.4\% (13/17), whilst its occurrence was low in Chongwe $39.1 \%$ (9/23). The occurrence of $E$. coli in other districts was almost the same (see Table 1).
One hundred and fifty samples were collected from the abattoirs, of which 78.7\% (118/150) E. coli and 2.67\% (4/150) Salmonella spp. were isolated. Out of the 118 E. coli, $31.4 \%$ (37/118) were isolated from abattoir A while 68.6\% (81/118) were isolated from abattoir B. All the Salmonella spp. isolates originated from abattoir B of which two were from cloacal swabs and two from carcass swabs.

Out of the three districts under study where open markets were sampled, 108 cloacal swabs were collected and only $E$. coli $36.1 \%$ (39/108) was isolated. In comparison with other districts sampled, $E$. coli isolates proportion was highest in Kitwe $42.4 \%$ (14/33), followed by Kabwe 35.0\% (14/40), and the lowest was Choma with $31.4 \%$ (11/35). 
Table 2. Overall antibiotic resistance patterns for E. coli isolates

\begin{tabular}{llllll}
\hline Antibiotic name & \% R & \%I & \% S & \% R 95\% C.I. & Number \\
\hline Ampicillin & 68.2 & 5.4 & 26.4 & $62.3-73.5$ & 280 \\
Amoxicillin/Clavulanic acid & 25.0 & 0.0 & 75.0 & $20.1-30.6$ & 280 \\
Cefotaxime & 22.5 & 4.3 & 73.2 & $17.8-27.9$ & 280 \\
Imipenem & 0.0 & 0.0 & 100.0 & - & 280 \\
Nalidixic acid & 45.0 & 16.1 & 38.9 & $39.1-51.0$ & 280 \\
Ciprofloxacin & 21.1 & 6.8 & 72.1 & $16.6-26.4$ & 280 \\
Trimethoprim/Sulfamethoxazole & 65.4 & 0.7 & 33.9 & $59.5-70.9$ & 280 \\
Chloramphenicol & 33.6 & 8.2 & 58.2 & $28.2-39.5$ & 280 \\
Tetracycline & 81.4 & 2.1 & 16.4 & $76.2-85.7$ & 280 \\
\hline
\end{tabular}

Note. $\mathrm{R}=$ Resistance, $\mathrm{I}=$ Intermediate, $\mathrm{S}=$ Susceptible and $95 \% \mathrm{CL}=9 \%$ Confidence Interval

Table 3. Antibiotic resistance patterns for $E$. coli isolated from litter in all districts sampled

\begin{tabular}{llllll}
\hline Antibiotic name & \% R & \%I & \%S & \% R 95\% C.I. & Number \\
\hline Ampicillin & 69.1 & 4.9 & 26.0 & $60.0-76.9$ & 123 \\
Amoxicillin/Clavulanic acid & 36.6 & 0.0 & 63.4 & $28.2-45.8$ & 123 \\
Cefotaxime & 22.0 & 5.7 & 72.4 & $15.2-30.5$ & 123 \\
Imipenem & 0.0 & 0.00 & 100.0 & - & 123 \\
Nalidixic acid & 39.8 & 18.7 & 41.5 & $31.2-49.0$ & 123 \\
Ciprofloxacin & 17.1 & 7.3 & 75.6 & $11.1-25.2$ & 123 \\
Trimethoprim/Sulfamethoxazole & 71.5 & 1.6 & 26.8 & $62.5-79.1$ & 123 \\
Chloramphenicol & 34.1 & 8.9 & 56.9 & $25.9-43.3$ & 123 \\
Tetracycline & 91.9 & 0.8 & 7.3 & $85.2-95.8$ & 123 \\
\hline
\end{tabular}

Note. $\mathrm{R}=$ Resistance, $\mathrm{I}=$ Intermediate, $\mathrm{S}=$ Susceptible and $95 \% \mathrm{CL}=9 \%$ Confidence Interval

Table 4. Antibiotic resistance patterns for E. coli isolated from cloacal and carcass swabs in abattoirs (Lusaka province).

\begin{tabular}{|c|c|c|c|c|c|}
\hline Antibiotic name & $\% \mathbf{R}$ & $\% \mathbf{I}$ & $\% \mathrm{~S}$ & $\%$ R $95 \%$ C.I. & Number \\
\hline Amoxicillin/Clavulanic acid & 10.2 & 7.6 & 82.2 & $5.6-17.5$ & 118 \\
\hline Ampicillin & 72.9 & 0.8 & 26.3 & $63.8-80.5$ & 118 \\
\hline Chloramphenicol & 39.0 & 6.8 & 54.2 & $30.3-48.4$ & 118 \\
\hline Ciprofloxacin & 28.0 & 6.8 & 65.3 & $20.3-37.1$ & 118 \\
\hline Cefotaxime & 27.1 & 1.7 & 71.2 & $19.5-36.2$ & 118 \\
\hline Imipenem & 0.0 & 0.0 & 100.0 & - & 118 \\
\hline Nalidixic acid & 53.4 & 12.7 & 33.9 & $44.0-62.6$ & 118 \\
\hline Trimethoprim/Sulfamethoxazole & 60.2 & 0.0 & 39.8 & $50.8-69.0$ & 118 \\
\hline Tetracycline & 71.2 & 2.5 & 26.3 & $62.0-79.0$ & 118 \\
\hline
\end{tabular}

Note. $\mathrm{R}=$ Resistance, $\mathrm{I}=$ Intermediate, $\mathrm{S}=$ Susceptible and $95 \% \mathrm{CL}=9 \%$ Confidence Interval

Table 5. E. coli susceptibility profile of cloacal samples from open markets in Choma, Kitwe, and Kabwe

\begin{tabular}{llllll}
\hline Antibiotic name & $\mathbf{\%}$ & $\mathbf{\%}$ & $\mathbf{\%}$ & $\mathbf{\%} \mathbf{R} \mathbf{9 5} \% \mathbf{C . I}$ & Number \\
\hline Ampicillin & 51.3 & 20.5 & 28.2 & $35.0-67.3$ & 39 \\
Amoxicillin/Clavulanic acid & 0.0 & 10.3 & 89.7 & $0.0-11.2$ & 39 \\
Cefotaxime & 10.3 & 7.7 & 82.1 & $3.4-25.2$ & 39 \\
Imipenem & 0.0 & 0.00 & 100.0 & $0.0-11.2$ & 39 \\
Nalidixic acid & 35.9 & 17.9 & 46.2 & $21.7-52.8$ & 39 \\
Ciprofloxacin & 12.8 & 5.1 & 82.1 & $4.8-28.2$ & 39 \\
Trimethoprim/Sulfamethoxazole & 61.5 & 0 & 38.5 & $44.6-76.2$ & 39 \\
Chloramphenicol & 15.4 & 10.3 & 74.4 & $6.4-31.2$ & 39 \\
Tetracycline & 79.5 & 5.1 & 15.4 & $63.1-90.1$ & 39 \\
\hline
\end{tabular}

Note. $\mathrm{R}=$ Resistance, $\mathrm{I}=$ Intermediate, $\mathrm{S}=$ Susceptible and $95 \% \mathrm{CL}=9 \%$ Confidence Interval 


\subsection{Antibiotic susceptibility testing}

One out of the four Salmonella spp. isolated exhibited resistance to 3 antibiotics namely, Amoxicillin-clavulanic acid (25\%, 95\% CI: $1.3 \%$ - 78.1\%), Ampicillin (25\%, 95\% CI: $1.3 \%-78.1 \%)$, and Cefotaxime $(25 \%, 95 \%$ CI: $1.3 \%$ $78.1 \%$ ). All the other isolates were $100 \%$ susceptible to all the other antibiotics tested. The antimicrobial profile of the $280 \mathrm{E}$. coli isolates revealed high sensitivity to imipenem $(100 \%, 95 \%$ CI $0.0-1.7)$ while the highest resistance was observed to tetracycline $(81.4 \%, 95 \%$ CI: $76.2-85.7 \%$ ) (see Table 2).

Isolates from the litter collected from poultry houses, showed very high resistance to tetracycline $(91.9 \%, 95 \%$ CI: 85.2 $-95.8 \%$ ), while all the isolates were $100 \%$ susceptible to imipenem (see Table 3).

All the 118 E. coli isolates from abattoirs revealed $100 \%$ susceptibility to Imipenem (see Table 4) but displayed variable resistance to $t$ the other antibiotics. Most of the isolates showed high resistance to ampicillin $(72.9 \%, 95 \%$ CI: 63.8 $-80.5 \%$ ), and the least resistance to amoxicillin/Clavulanic acid $(10.2 \%, 95 \%$ CI: $5.6-17.5 \%)$.

Overall, the isolates obtained from open markets in Choma, Kabwe and Kitwe, showed a similar resistance pattern to what was observed at the farms and the abattoir, with the highest resistance to tetracycline $(79.5 \%, 95 \%$ CI: 63.1 $90.1 \%$ ) and $100 \%$ susceptibility to imipenem and amoxicillin/clavulanic acid (see Table 5). Comparing the 3 districts were cloacal samples were collected from open markets, the highest resistance to tetracycline were samples from Choma $81.8 \%$, followed by Kitwe (85.7\%) and Kabwe (71.4\%).

\subsection{Multidrug resistance and resistance profiles}

Out of the 280 isolates subjected to antimicrobial susceptibility testing, $94.6 \%(265 / 280)$ were resistant to one or more antibiotics. Furthermore, $75.7 \%$ (237/280) of the E. coli isolates showed resistance to three or more classes of antibiotics, indicating multi-drug resistance (MDR). MDR was defined as non-susceptibility to three or more antimicrobial classes tested. ${ }^{[23]}$ The highest MDR profile was observed in $8.2 \%$ $(23 / 280)$ isolates in which 6 out of the 9 classes of antibiotics tested were resistant. These classes of antibiotics include the folate inhibitors, fluoroquinolones, penicillin's, phenicol's, quinolones, and tetracyclines. Out of the 280 isolates, 11.4\% (32/280) exhibited Extensive Drug resistance (XDR) which is non-susceptibility in all but 2 or fewer antimicrobial categories in the antimicrobial classes tested.

\section{Discussion}

This study found antibiotic-resistant Salmonella spp. and $E$. coli in broiler chickens at farm level, the abattoirs, and open markets in selected districts of Zambia. These bacteria are of public health importance in the sense that they may be transferred to humans. There was no Salmonella spp. isolated from chicken litter at farms or live chicken cloacal swabs at open markets, but four Salmonella spp. were isolated from chickens at an abattoir in Lusaka. The Salmonella spp. isolated from the abattoirs in this study corroborates the findings by Mpundu P. et al (2019) and Shamaila T. et al (2018) who conducted studies in abattoirs with a similar set-up and reported proportions of $2.6 \%$ and $2.0 \%$, respectively. ${ }^{[24,25]}$ However, the frequency of isolation was lower than what was found in two previous studies conducted in Zambia, in which one reported $28 \%{ }^{[26]}$ and the other $16.2 \% .^{[27]}$ This could be attributed to the identification methods used as Hang'ombe et al (1999), only used biochemical tests for definitive diagnosis of Salmonella spp., while, both biochemicals and molecular tests were used in this study, thereby improving the validity of the current findings.

Contrary to our findings, studies that were done in Spain ${ }^{[28]}$ and Turkey ${ }^{[29]}$ found a high prevalence of Salmonella spp. of $43.6 \%$ and $60.0 \%$ respectively. The difference in our findings could be attributed to the sampling methods used in these studies. Carramiñana JJ et al, (2004) collected samples over a long period and Goksoy E.O. et al (2004), sampled only at critical control points. ${ }^{[28,29]}$ It is reported that the frequency of Salmonella spp. isolation in an infected host is affected by the biological nature of the pathogen and its shedding pattern, which is seasonal and depends on environmental factors. ${ }^{[30,31]}$

This study found a high proportion of $E$. coli at abattoir level and low proportion from open markets and farms, similar to previous findings in studies done in Zambia ${ }^{[11,26]}$ that had a high isolation rate of E. coli. with confirmed extendedspectrum $\beta$-lactamases (ESBLs). The widespread antibiotic usage for prophylaxis and treatment is the main risk factor for an increase in the occurrence of bacterial resistant strains. Our findings however were different from a study conducted in Spain ${ }^{[32]}$ that had a higher isolation rate from open markets and farms. Many factors could have contributed to this, among them antibiotic usage and seasonal variation. ${ }^{[31,33]}$ Seasonal variation affecting the rate of bacterial shedding has also been reported in other studies that found the isolation of Salmonella spp. to be higher in high temperatures in comparison to cooler temperatures. ${ }^{[34,35]}$

Similar to the findings in this study, a study was done in Turkey by Goksoy et al, that sampled broiler chickens des- 
tined for slaughter found chickens to be highly contaminated with bacteria, especially with potential human pathogenic bacteria such as coliforms and Salmonella spp. ${ }^{[29]}$ In this particular study, high contamination levels of $E$. coli on chicken carcasses were associated with carcass contamination with gut products, which occur during the process of evisceration.

Salmonella spp. isolates in this study indicate fairly low resistance of $25 \%$ resistance to amoxicillin-clavulanic acid, ampicillin, and cefotaxime. This is similar to what was reported in India in which resistance was $18 \%$ amoxicillin-clavulanic acid, $18 \%$ ampicillin, $20 \%$ cefotaxime $^{[36]}$ and those reported in the United States in which they found the resistance of $1 \%$ amoxicillin-clavulanic acid, $26 \%$ ampicillin, and $0 \%$ Ceftriaxone. ${ }^{[16]}$ The frequency and extent of Salmonella spp. resistance to antimicrobial drugs varies based on their usage in animal production and humans as well as on ecological differences in the epidemiology of Salmonella spp. infections. ${ }^{[37]}$ This can be evidenced by studies done over a long period by Zhao S. et al conducted in the U.S. between 2002 and 2006 in retail meat supply in which he found varying frequencies and extent of Salmonella spp. resistance. ${ }^{[38]}$ In his study on the epidemiology of resistance to antibiotics linking animals and humans, Van den Bogaard et al (2000), found that resistant commensal bacteria of food animals might contaminate, like zoonotic bacteria, meat (products) then reach the intestinal tract of humans. This further demonstrates that not only clonal spread of resistant strains occurs, but also the transfer of resistance genes between human and animal bacteria. ${ }^{[39]}$

E. coli resistance to imipenem was low in this study. This is similar to other studies done in the USA in a study by Davis G.S et al (2018) and the United Kingdom by Randal L.P et al (2017) in which they found zero resistance of E. Coli to Imipenem. ${ }^{[40,41]}$ This could be attributed to the fact that imipenem is one of the last line of antibiotics for treating human bacterial infections and is not often used in food production. ${ }^{[42]}$ Although colistin was not tested in this study, it was noticed that some farmers administered veterinary products containing colistin as an active compound. Due to the increased exposure and sub-optimal dosages, increased resistance to this class of antibiotics which is considered as the last resort treatment in humans infected with Extensive Drud Resistance (XDR) gram-negative pathogens is inevitable. Of note, high levels of resistance to tetracycline in both farm and open market samples was observed. A study done by Chishimba et al (2016) observed that $45.5 \%$ of the E. coli isolates exhibited Multi-Drug Resistance (MDR) to six or more antibiotics tested. ${ }^{[11]}$ These findings were comparable or slightly lower to our results that found an overall MDR of 75.7\% (212/280) and 29.3\% (82/280) MDR to six or more antibiotics E. coli isolates. In this study, the highest multi-drug resistance (MDR) was observed to the following antibiotics ampicillin, tetracycline, and trimethoprim/sulfamethoxazole. These findings were in agreement with other studies done in Iran, USA, India, Brazil, Thailand, and Southern African, ${ }^{[1,16,36,43-45]}$ that revealed MDR in Enterobacteriaceae, including Salmonella spp. and E. coli. Similarly, a study conducted in Zambia, observed that $E$. coli isolates from cattle had high resistance to sulfamethoxazole/trimethoprim, ciprofloxacin, ampicillin, and tetracycline. ${ }^{[14]}$

These findings can be attributed to the use of antibiotics as growth promoters. ${ }^{[1,46]}$ Tetracycline has also been used as a growth enhancer and a therapeutic agent in food production, ${ }^{[43]}$ hence the high level of resistance observed in this study is not surprising. In Zambia, tetracycline has been used extensively to treat diseases and has given rise to the resistance. ${ }^{[47]}$ Some of the major factors leading to AMR in E. coli include antibiotic use, overcrowding, and poor sanitation. ${ }^{[8,48]}$ These factors are typical of intensive poultry farming and explain the prevalence and degree of resistance in E. coli isolated from poultry litter at the farms. ${ }^{[7]}$

In another study, Byarugaba D. et al (2004) $)^{[12]}$ found that the use of antimicrobials as growth promoters, therapeutic and, prophylactic agents has greatly influenced the prevalence of resistance in animal bacteria thus a posing a risk of antibiotic resistance in human pathogens. ${ }^{[12]}$ The author further observed that isolates that are resistant to two or more antibiotics may have originated from high-risk sources of contamination like commercial poultry farms, where antibiotics are commonly used. ${ }^{[12]}$

In this study, it was observed that most of the isolates $94.6 \%$ (265/280) were resistant to more than one antibiotic. This is consistent with the study done in developing countries by Byarugaba et al, which provided direct evidence that antimicrobial use in animals selects for antimicrobial-resistant bacteria that may be transferred to humans through food or direct contact with the animals. ${ }^{[12]}$ This was also in consonance with previous findings in a study conducted at the University Teaching Hospital in Lusaka, Zambia, on stool samples obtained from children under the age of 5 years, in which Salmonella spp. and E. coli were also found to be multidrug-resistant. ${ }^{[49]}$

\section{CONCLUSION AND RECOMMENDATION}

This study revealed that both Salmonella spp. and E. coli are resistant to several antibiotics of both animal and human importance with similar patterns at all three levels: farm, abattoir, and open markets. The resistance patterns in both 
species found in food meant for human consumption constitute a major public health concern. This study has further shown that MDR of Salmonella spp. and E. coli in broiler chickens may largely contribute to the wider and broad challenge of antimicrobial resistance. The overall implication of continued use of antibiotics as growth promoters and for prophylaxis, especially the antibiotics reserved for human consumption is that the antibiotic treatment options will be limited thereby leading to increased morbidity and mortality. More studies need to be done on the abattoir workers (hands and fecal samples) to gain insight into their possible contribution to poultry meat AMR bacteria contamination.

\section{REFERENCES}

[1] Talebiyan R, Kheradmand M, Khamesipour F, et al. Multiple antimicrobial resistance of Escherichia coli isolated from chickens in Iran. Veterinary medicine international. 2014; 2014. PMid:25548716. https://doi.org/10.1155/2014/491418

[2] Rouger A, Tresse O, Zagorec M. Bacterial contaminants of poultry meat: sources, species, and dynamics. Microorganisms. 2017 5(3): 50. PMid:28841156. https://doi.org/10.3390/microo rganisms 5030050

[3] Barbour EK, Ayyash DB, Alturkistni W, et al. Impact of sporadic reporting of poultry Salmonella serovars from selected developing countries. The Journal of Infection in Developing Countries. 2015; 9(01): 001-7. PMid:25596565. https://doi.org/10.3855/ji dc. 5065

[4] Morobe I, Obi C, Nyila MA, et al. Prevalence, antimicrobial resistance profiles of Listeria monocytognes from various foods in Gaborone, Botswana. African Journal of Biotechnology. 2009; 8(22) https://doi.org/10.5897/AJB2009.000-9486

[5] Taylor EV, Herman KM, Ailes E, et al. Common source outbreaks of Campylobacter infection in the USA, 1997-2008. Epidemiology \& Infection. 2013; 141(5): 987-96. PMid:22892294. https : //doi.org/10.1017/S0950268812001744

[6] Ferri M, Ranucci E, Romagnoli P, et al. Antimicrobial resistance: a global emerging threat to public health systems. Critical reviews in food science and nutrition. 2017; 57(13): 2857-76. PMid:26464037. https://doi.org/10.1080/10408398.2015.1077192

[7] Van den Bogaard A, Willems R, London N, et al. Antibiotic resistance of fecal enterococci in poultry, poultry farmers, and poultry slaughterers. Journal of Antimicrobial Chemotherapy. 2002; 49(3): 497-505. PMid:11864950. https://doi.org/10.1093/jac/49.3.497

[8] Van den Bogaard A, London N, Driessen C, et al. Antibiotic resistance of fecal Escherichia coli in poultry, poultry farmers, and poultry slaughterers. Journal of Antimicrobial Chemotherapy. 2001; 47(6): 763-71. PMid:11864950. https://doi.org/10.1093/jac/49.3 .497

[9] Petrovic J, Plavsa N, Milanov D, et al. Antimicrobial resistance of foodborne pathogens as a food safety issue. lucrari Scientific. 2010; 43(2): 197-203.

[10] Ministry of Fisheries and Livestock, The Zambian Poultry Industry. 2019.

[11] Chishimba K, Hang'Ombe B, Muzandu K, et al. Detection of extended-spectrum beta-lactamase-producing Escherichia coli in market-ready chickens in Zambia. International Journal of Microbiology. 2016; 2016. PMid:27190518. https ://doi .org/10.1155/ $2016 / 5275724$

\section{ACKNOWLEDGEMENTS}

We would like to thank the World Bank-funded African Centre of Excellence in Infectious Diseases of Humans and Animals (ACEIDHA) Project and the CAPAZOMANITECO Project at the University of Zambia for the support provided during this study. We would like to thank Mr. Joseph Ndebe, Mr. Penjani Kapila, Dr. Alfred Mangani, Ms. Musonda Mubanga, and Dr. Wiza Mwasinga for their technical support and guidance rendered during this study.

\section{CONFlicts OF InTEREST Disclosure}

The authors declare that they have no competing interests.

[12] Byarugaba D. Antimicrobial resistance in developing countries and responsible risk factors. International Journal of Antimicrobial agents. 2004; 24(2): 105-10. PMid:15288307. https://doi .org/10.101 6/j.ijantimicag. 2004.02.015

[13] Duffy G, Lynch O, Cagney C. Tracking emerging zoonotic pathogens from farm to fork. Meat science. 2008; 78(1-2): 34-42. PMid:22062093. https://doi.org/10.1016/j.meatsci. 2007 .05 .023

[14] Mainda G, Bessell PR, Muma JB, et al. Prevalence and patterns of antimicrobial resistance among Escherichia coli isolated from Zambian dairy cattle across different production systems. Scientific reports. 2015; 5: 12439. PMid:26211388. https://doi.org/10.1038/sr ep12439

[15] Hitchins A, Feng P, Watkins W, et al. Food and Drug Administration Bacteriological Analytical Manual. Gaithersburg, USA: AOAC International; 1995.

[16] Logue C, Sherwood J, Olah P, et al. The incidence of antimicrobialresistant Salmonella spp. on freshly processed poultry from US Midwestern processing plants. Journal of applied microbiology. 2003; 94(1): 16-24. https://doi.org/10.1101/2020.04.20.05091 4

[17] Morgan-Linnell SK, Stewart DJ, Kurzrock R. US Food and Drug Administration inspections of clinical investigators: an overview of results from 1977 to 2009. Clinical Cancer Research. 2014; 20(13): 3364-70. PMid:24737548. https ://doi .org/10.1158/1078-0 432. CCR-13-3206

[18] Ed-dra A, Filali FR, Karraouan B, et al. Prevalence, molecular and antimicrobial resistance of Salmonella isolated from sausages in Meknes, Morocco. Microbial pathogenesis. 2017; 105: 340-5. PMid:28258000. https://doi .org/10.1016/j . micpath. 2017 .02 .042

[19] Ed-Dra A, Filali FR, Khayi S, et al. Antimicrobial resistance, virulence genes, and genetic diversity of Salmonella enterica isolated from sausages. European Journal of Microbiology and Immunology. 2019; 9(2): 56-61. PMid:31223497. https ://doi .org/10.1556/ 1886.2018 .00035

[20] Biemer JJ. Antimicrobial susceptibility testing by the Kirby-Bauer disc diffusion method. Annals of Clinical \& Laboratory Science. 1973; 3(2): 135-40.

[21] Organization WH. Integrated surveillance of antimicrobial resistance in foodborne bacteria: application of a one health approach: guidance from the WHO Advisory Group on Integrated Surveillance of Antimicrobial Resistance (AGISAR). 2017.

[22] Edition AS-T. Clinical and Laboratory Standards Institute. Wayne, Pa. 2009. 
[23] Magiorakos A-P, Srinivasan A, Carey R, et al. Multidrug-resistant, extensively drug-resistant and pan drug-resistant bacteria: an international expert proposal for interim standard definitions for acquired resistance. Clinical microbiology and infection. 2012; 18(3): 268-81. PMid:21793988. https://doi .org/10.1111/j.1469-0691.20 $11.03570 . x$

[24] Mpundu P, Munyeme M, Zgambo J, et al. Evaluation of bacterial Contamination in dressed Chickens at Lusaka Abattoirs. Frontiers in public health. 2019; 7: 19. PMid:30838192. https://doi .org/10 .3389/fpubh. 2019.00019

[25] Shamaila T, Ndashe K, Kasase C, et al. Inva gene and antibiotic susceptibility of Salmonella Spp isolated from commercially processed broiler carcasses In Lusaka District, Zambia. 2018. https : //doi.org/10.14500/icpas2018.mim100

[26] Hang'ombe BM, Sharma NR, Skjerve E, et al. Isolation of bacteria during processing of chicken carcasses for the market in Lusaka, Zambia. Veterinarski arhiv. 1999; 69(4): 191-7. PMid:22988514. https://doi.org/10.1155/2012/520564

[27] William UD, Hang'ombe B, Victor ZC, et al. Distribution of virulence genes and antimicrobial susceptibility of Salmonella isolated from dogs and chickens in Zambia. 2012.

[28] Carramiñana JJ, Rota C, Agustin I, et al. High prevalence of multiple resistance to antibiotics in Salmonella serovars isolated from a poultry slaughterhouse in Spain. Veterinary Microbiology. 2004; 104(1-2): 133-9. PMid:15530748. https://doi.org/10.1016/j. vetmic. 2004.08.010

[29] Goksoy EO, Kirkan S, Kok F. Microbiological quality of broiler carcasses during processing in two slaughterhouses in Turkey. Poultry science. 2004; 83(8): 1427-32. PMid:15339020. https://doi or $\mathrm{g} / 10.1093 / \mathrm{ps} / 83.8 .1427$

[30] Davies R, Wray C. Seasonal variations in the isolation of Salmonella typhimurium, Salmonella enteritidis, Bacillus cereus and Clostridium perfringens from environmental samples. Journal of Veterinary Medicine, Series B. 1996; 43(1-10): 119-27. PMid:8693843. https://doi.org/10.1111/j.1439-0450.1996.tb00295.x

[31] Phillips I, Casewell M, Cox T, et al. Does the use of antibiotics in food animals pose a risk to human health? A critical review of published data. Journal of Antimicrobial Chemotherapy. 2004; 53(1): 28-52. PMid:14657094. https://doi.org/10.1093/jac/dkg483

[32] Egea P, López-Cerero L, Torres E, et al. Increased raw poultry meat colonization by extended spectrum beta-lactamase-producing Escherichia coli in the south of Spain. International journal of food microbiology. 2012; 159(2): 69-73. PMid:23072690. https: //doi.org/10.1016/j.ijfoodmicro.2012.08.002

[33] Apata D. Antibiotic resistance in poultry. International Journal of Poultry Science. 2009; 8(4): 404-8. https://doi.org/10.3923/ ijps. 2009.404.408

[34] Parveen S, Lukasik J, Scott T, et al. Geographical variation in antibiotic resistance profiles of Escherichia coli isolated from swine, poultry, beef, and dairy cattle farm water retention ponds in Florida 1. Journal of Applied Microbiology. 2006; 100(1): 50-7. PMid:16405684. https://doi.org/10.1111/j.1365-2672.2005.02773.x

[35] Hudson J, Nicol C, Wright J, et al. Seasonal variation of Campylobacter types from human cases, veterinary cases, raw chicken, milk, and water. Journal of Applied Microbiology. 1999; 87(1): 115-24. PMid:10432592. https://doi.org/10.1046/j.1365-2672.19 99.00806.x

[36] Arora D, Kumar S, Singh D, et al. Isolation, characterization, and antibiogram pattern of Salmonella from poultry in parts of Haryana, India. Adv Anim Vet Sci. 2013; 1(5): 161-3. http://www. nexusa cademicpublishers.com/journal/4
[37] Zhao S, White D, Friedman S, et al. Antimicrobial resistance in Salmonella enterica serovar Heidelberg isolates from retail meats, including poultry, from 2002 to 2006. Applied and environmental microbiology. 2008; 74(21): 6656-62. PMid:18757574. https : //doi.org/10.1128/AEM.01249-08

[38] Zhao S, Blickenstaff $\mathrm{K}$, Glenn A, et al. $\beta$-Lactam resistance in Salmonella strains isolated from retail meats in the United States by the National Antimicrobial Resistance Monitoring System between 2002 and 2006. Applied and environmental microbiology. 2009; 75(24): 7624-30. https://doi.org/10.1128/AEM.01249-09

[39] Van den Bogaard AE, Stobberingh EE. Epidemiology of resistance to antibiotics: links between animals and humans. International journal of antimicrobial agents. 2000; 14(4): 327-35. https : //doi.org/10.1016/S0924-8579(00) 00145-X

[40] Davis GS, Waits K, Nordstrom L, et al. Antibiotic-resistant Escherichia coli from retail poultry meat with different antibiotic use claims. BMC microbiology. 2018; 18(1): 174. PMid:30390618. https://doi.org/10.1186/s12866-018-1322-5

[41] Randall L, Lodge M, Elviss N, et al. Evaluation of meat, fruit, and vegetables from retail stores in five United Kingdom regions as sources of extended-spectrum beta-lactamase (ESBL)-producing and carbapenem-resistant Escherichia coli. International Journal of Food Microbiology. 2017; 241: 283-90. PMid:27821357. https: //doi.org/10.1016/j.ijfoodmicro.2016.10.036

[42] Health WOfA. OIE list of antimicrobials of veterinary importance. 75th General Session in May 2007. 2007.

[43] Cardoso MO, Ribeiro AR, Santos LRd, et al. Antibiotic resistance in Salmonella Enteritidis isolated from broiler carcasses. Brazilian Journal of Microbiology. 2006; 37(3): 368-71. https ://doi .org/ 10.1590/S1517-83822006000300030

[44] Hanson R, Kaneene JB, Padungtod P, et al. Prevalence of Salmonella and E. coli, and their resistance to antimicrobial agents, in farming communities in northern Thailand. Southeast Asian Journal of Tropical Medicine and Public Health. 2003; 33: 1206. https://doi.org/10.5713/ajas.2012.12023 PMid:25049697 PMCid:PMC4092948

[45] Mshana SE, Matee M, Rweyemamu M. Antimicrobial resistance in human and animal pathogens in Zambia, Democratic Republic of Congo, Mozambique and Tanzania: an urgent need of a sustainable surveillance system. Annals of clinical microbiology and antimicrobials. 2013; 12(1): 28. PMid:24119299. https ://doi.org/10.1 186/1476-0711-12-28

[46] Ramchandani M, Manges AR, DebRoy C, et al. Possible animal origin of human-associated, multidrug-resistant, uropathogenic Escherichia coli. Clinical Infectious Diseases. 2005; 40(2): 251-7. PMid:15655743. https://doi.org/10.1086/426819

[47] Mainda G, Bessell PR, Muma JB, et al. Erratum: Prevalence and patterns of antimicrobial resistance among Escherichia coli isolated from Zambian dairy cattle across different production systems. Scientific reports. 2015; 5: 14162. PMid:26211388. https: //doi.org/10.1038/srep12439

[48] Diarrassouba F, Diarra MS, Bach S, et al. Antibiotic resistance and virulence genes in commensal Escherichia coli and Salmonella isolates from commercial broiler chicken farms. Journal of food protection. 2007; 70(6): 1316-27. PMid:17612058. https://doi.org/ 10.4315/0362-028X-70.6.1316

[49] Chiyangi H, Muma JB, Malama S, et al. Identification and antimicrobial resistance patterns of bacterial enteropathogens from children aged 0-59 months at the University Teaching Hospital, Lusaka, Zambia: a prospective cross-sectional study. BMC infectious diseases. 2017; 17(1): 117. PMid:28152988. https://doi.org/10.1186/ s12879-017-2232-0 